\title{
Coping with stress in adults with speech fluency disorders
}

\author{
Magdalena Pietraszek ${ }^{A, B, D, F, G}$, Marta Lockiewicz $^{A, C, D, E, F}$, Anna Jankowska ${ }^{D, E, F}$ \\ Institute of Psychology, University of Gdansk, Gdansk, Poland
}

\section{BACKGROUND}

Stuttering is a developmental speech disorder that affects the fluency of speech. Persons who stutter perceive speaking situations and social interactions as threatening.

\section{PARTICIPANTS AND PROCEDURE}

Nineteen (47.50\%) adults with speech fluency disorders (SFD) and 21 (52.50\%) without participated in the study. All participants completed the following measures individually: the State-Trait Anxiety Inventory, the Coping Inventory for Stressful Situations (CISS), and an informational survey.

\section{RESULTS}

Our study confirmed that persons with SFD experience more stressful situations in life and feel greater anxiety, both as a trait and as a state, which influences their daily life. The negative affect experienced contributed to their preferred use of Emotion-Oriented Coping strategies, at the expense of more proactive Task-Oriented Coping. Experienced stress and anxiety influenced and consolidated their habitual stress coping styles, devoted mainly to dealing with negative emotions.

\section{CONCLUSIONS}

Stuttering affects daily activities, interpersonal relationships, and the quality of life. Therefore, professional support should include adaptive, task-oriented coping.

\section{KEY WORDS}

quality of life; anxiety; stuttering

CORresponding AUthor - Marta Łockiewicz, Ph.D., Institute of Psychology, 4 Bażyńskiego Str., 80-309 Gdansk, Poland, e-mail: psymlo@univ.gda.pl

Authors' Contribution - A: Study design · B: Data collection · C: Statistical analysis · D: Data interpretation ·

E: Manuscript preparation · F: Literature search · G: Funds collection

to CITE THIS ARTICLE - Pietraszek, M., Łockiewicz, M., \& Jankowska, A. (2017). Coping with stress in adults with speech

fluency disorders. Current Issues in Personality Psychology, 5(2), 143-148.

RECEIVED 12.09.2016 · REVIEWED 16.10.2016 · ACCEPTED 04.11.2016 · PUBLISHED 16.12.2016 


\section{BACKGROUND}

Stuttering, a developmental communication disorder that has its onset in childhood, affects the normal, expected fluency and time patterning of speech (American Psychiatric Association, 2013). Frequent and severe disfluencies that distinctly interrupt the production and flow of speech include pauses, circumlocutions, and involuntary repetitions and prolongations of sounds, syllables, and words (APA, 2013; WHO, 1992). Although no specific cause of developmental stuttering has been identified yet, a large number of studies indicate its neurological origins (Namasivayam \& van Lieshout, 2008).

Persons who stutter perceive speaking situations and social interactions as threatening (Plexico, Manning, \& DiLollo, 2005). Since the inability to present thoughts in a spontaneous and fluent manner can be frightening, embarrassing, and/or frustrating (Craig \& Tran, 2006), it impacts self-esteem and self-image (Klompas \& Ross, 2004), and results in increased levels of anxiety compared to those characteristic of persons who do not stutter (Craig, Hancock, Tran, \& Craig, 2003).

Social discomfort and anxiety related to oral communication pressure persons with speech fluency disorders (SFD) to develop strategies to manage and respond to the emotional threat. The problemfocused strategies focus on generating constructive solutions to a problem by applying productive efforts (e.g. recognizing a problem, analyzing possible solutions) to eliminate or alter the source of the threat (Carver \& Scheier, 1994). The emotion-focused strategies concentrate on decreasing and managing threatening emotions and emotional responses to a difficult problem. When persons sense that they can fix the problem in a constructive manner, the problemfocused approach is predominant. When persons think that a stressful situation needs to be endured, the emotion-focused coping strategies are preferred.

Erdem, Çelik, Doruk, Özgen, and Özşahin (2011) found that adults who stutter obtained low scores in both adaptive coping strategies (i.e. problem-focused and emotion-focused strategies). Instead, they more often tended to apply dysfunctional coping strategies. Maladaptive responses include denial, wishful thinking, self-blame, and cognitive or behavioral disengagement, and are harmful if applied long term (Carver \& Scheier, 1994).

Vanryckeghem, Brutten, Uddin, and Van Borsel (2004) reported that during or before a speaking situation, persons who stutter demonstrate a greater number of behavioral coping responses, such as body movements (e.g. "finger tapping and leg movements"), and speech-related strategies (e.g. "pretending not to know the answer to a question"). Stuttering persons avoid speaking situations because of their embarrassment, anxiety, and awareness that their disfluent speech causes discomfort to their interlocutor (Plexico, Manning, \& Levitt, 2009).

Effective coping with stuttering-related anxiety regulates the quality of life of adults who stutter (Crichton-Smith, 2002; Koedoot, Bouwmans, Franken, \& Stolk, 2011; Vanryckeghem et al., 2004). Avoidance, though, brings a temporary solution to shortterm difficulties, while it leads to harmful social, professional, and psychological outcomes (Blumgart, Tran, \& Craig, 2010).

The aim of our study was to examine the relationship between state and trait anxiety, and the employed stress coping styles. We hypothesized that participants with SFD, as compared with participants without SFD, would more often experience a higher level of state and trait anxiety, due to the experienced threatening and stressful speaking situations, as suggested in the literature (APA, 2013; Craig et al., 2003). We assumed that participants who stutter would more often use Emotion-Oriented and Avoidance Coping with stress style, and less often use Task-Oriented Coping. We hypothesized that state and trait anxiety lead to the application of Emotion-Oriented and Avoidance coping strategies, at the expense of Task-Oriented coping. We decided to study adults, as they had had long experience with SFD symptoms, to better present the impact of longitudinal exposure to stressful situations on anxiety and coping.

\section{PARTICIPANTS AND PROCEDURE}

1. The State-Trait Anxiety Inventory (STAI) by Spielberger, Gorsuch, and Lushene: a two-part scale measuring trait and state anxiety. We used the Polish adaptation by Spielberger, Strelau, Tysarczyk, and Wrześniewski (Sosnowski, Wrześniewski, Jaworowska, \& Fecenec, 2011). Participants rate 40 items (20 for trait and 20 for state anxiety) on a 4-point scale (e.g. from "definitely yes" to "definitely not"). Higher scores indicate greater anxiety. Internal consistency coefficients for adult males and females have ranged from .76 to .92 . Test-retest reliability coefficients have ranged from .39 to .81 over a 3-4 week interval.

2. Coping Inventory for Stressful Situations (CISS) by Endler and Parker: a scale measuring three types of coping styles: Task-Oriented Coping, Emotion-Oriented Coping, and Avoidance-Oriented Coping (2 subscales: Distraction and Social Diversion). We used the Polish adaptation by Szczepaniak, Strelau, and Wrześniewski (Strelau, Jaworowska, Wrześniewski, \& Szczepaniak, 2005). Participants rate 48 items (16 for each coping style) on a 5-point scale, evaluating the frequency with which they behave in a given way in a stressful situation. Internal consistency coefficients 
have ranged from .84 to .86 . Test-retest reliability coefficients have ranged from .73 to .80 over a $2-3$ week interval.

3. A set of questions developed by the authors. Open questions concerned age, gender, stuttering report, and psychological and speech therapy. Moreover, participants with SFD rated 10 items which concerned social relations, speech anxiety, and experienced stress on a 5-point scale (e.g. self-assessment from "definitely not" to "definitely yes" of a question: I encounter many stressful situations on a daily basis).

\section{PARTICIPANTS}

Nineteen (47.50\%) adults with SFD, and 21 (52.50\%) without SFD, including 18 (45\%) females and 22 (55\%) males, participated in the study. They were matched for age $\left(M_{\text {age }}=34.42, S D_{\text {age }}=14.46\right.$, range: 18 to 61 years, for the criterion group, $M_{\text {age }}=38.33, S D_{\text {age }}=20.27$, $M d n=30$, range: 18 to 81 years), for the control group, $t(38)=0.70, p=.491)$. All participants with SFD took part in speech therapy; almost half of them (8 persons; $42 \%$ ) also took part in psychological therapy. This suggests that they continued to manifest speech disfluencies, and experienced problems in everyday psychological and social functioning in adult life. No one in the control group took part in either speech or psychological therapy. Each participant expressed informed consent to participate. All participants took part individually; they completed the two inventories and the survey given to them by the experimenter.

All statistical calculations were computed using the raw data. We used either the $t$-test or the Mann-Whitney test, where appropriate, based on the dependent variable distribution.

\section{RESULTS}

Participants with SFD $(M=60.05, S D=4.01)$ experienced a higher degree of state anxiety than their peers without SFD $(M=38.62, S D=5.03)$ $(t(38)=14.79, p<.001, d=2.57)$, as well as of trait anxiety $(M=57.00, S D=3.53$ for the criterion group, $M=38.14, S D=4.41$ for the control group, $t(38)=14.83$, $p<.001, d=4.75)$ (Table 1$)$. They also $(M d n=31)$ more rarely used the Task-Oriented Coping style than the controls did $(M d n=55, U=2.50, Z=5.35, p<.001$, $r=.84)$. Instead, the participants with SFD $(M=70.58$, $S D=3.37)$ more often used Emotion-Oriented Coping than their peers without SFD $(M=37.86, S D=3.02)$ $(t(30)=32.38, p<.001, d=10.24)$. They also $(M=16.32, S D=2.06)$ more rarely used Avoidance-Oriented Coping: Distraction than the controls $\operatorname{did}(M=19.86, S D=2.50)(t(38)=4.87, p<.001$, $d=1.55)$, as well as Avoidance-Oriented Coping: Social Diversion $(M=12.53, S D=2.59$ for the criterion group, $M=16.43, S D=1.75$ for the control group) $(t(38)=5.63, p<.001, d=1.80)$.

An analysis of correlation (calculated for all participants; Table 2) revealed that state anxiety correlated negatively with Task-Oriented Coping, Avoidance-Oriented Coping: Distraction, and Avoidance-Oriented Coping: Social Diversion, and positively with Emotion-Oriented Coping. Trait anxiety correlated negatively with Task-Oriented Coping, Avoidance-Oriented Coping: Distraction, and Avoidance-Oriented Coping: Social Diversion, and positively with Emotion-Oriented Coping.

These findings were confirmed by a linear regression (calculated for all participants), which demonstrated the influence of trait and state anxiety on the preferred strategies of coping with stress. Trait anxiety predicted: Task-Oriented Coping, $R^{2}=.77$,

Table 1

Anxiety and stress coping styles in speech fluency disorders (SFD)

\begin{tabular}{|c|c|c|c|c|c|c|c|c|}
\hline & \multicolumn{2}{|c|}{$\begin{array}{l}\text { Adults with } \\
\text { SFD }\end{array}$} & \multicolumn{2}{|c|}{$\begin{array}{l}\text { Adults without } \\
\text { SFD }\end{array}$} & \multirow[t]{2}{*}{$t(38)$} & \multirow[t]{2}{*}{$p$} & \multirow[t]{2}{*}{$d$} & \\
\hline & $M$ & $S D$ & $M$ & $S D$ & & & & \\
\hline Trait anxiety & 57.00 & 3.53 & 38.14 & 4.41 & 14.79 & $<.001$ & 4.75 & \\
\hline State anxiety & 60.05 & 4.01 & 38.62 & 5.03 & 14.79 & $<.001$ & 2.57 & \\
\hline Emotion-Oriented Coping & 70.58 & 3.37 & 37.86 & 3.02 & $\begin{array}{c}32.38 \\
(30)\end{array}$ & $<.001$ & 10.24 & \\
\hline $\begin{array}{l}\text { Avoidance-Oriented Coping: } \\
\text { Distraction }\end{array}$ & 16.32 & 2.06 & 19.86 & 2.50 & 4.87 & $<.001$ & 1.55 & \\
\hline \multirow[t]{2}{*}{$\begin{array}{l}\text { Avoidance-Oriented Coping: } \\
\text { Social Distraction }\end{array}$} & 12.53 & 2.59 & 16.43 & 1.75 & 5.63 & $<.001$ & 1.80 & \\
\hline & \multicolumn{2}{|c|}{$M d n$} & \multicolumn{2}{|c|}{$M d n$} & $U$ & $Z$ & $p$ & $r$ \\
\hline Task-Oriented Coping & \multicolumn{2}{|c|}{31} & \multicolumn{2}{|c|}{55} & 2.50 & 5.35 & $<.001$ & .84 \\
\hline
\end{tabular}


Table 2

Anxiety and stress coping styles: correlations in both groups

\begin{tabular}{lccccc}
\hline & & \multicolumn{4}{c}{ Coping Style } \\
\cline { 3 - 5 } & & $\begin{array}{c}\text { Avoidance } \\
\text { Distraction }\end{array}$ & $\begin{array}{c}\text { Avoidance: } \\
\text { Social Diversion }\end{array}$ & Task-Oriented & Emotion-Oriented \\
\hline \multirow{2}{*}{ State anxiety } & $r$ & -.51 & -.60 & -.83 & .90 \\
& $p$ & $<.001$ & $<.001$ & $<.001$ & $<.001$ \\
Trait anxiety & $r$ & -.57 & -.65 & -.86 & .90 \\
& $p$ & $<.001$ & $<.001$ & $<.001$ & $<.001$ \\
\hline
\end{tabular}

$F(2,37)=62.07, p<.001, \beta=-.37, t=-2.48, p<.001$, accounting for $14 \%$ of variance, Emotion-Oriented Coping, $R^{2}=.88, F(2,37)=130.17, p<.001, \beta=.51$, $t=4.64, p<.001$, accounting for $37 \%$ of variance, and Avoidance-Oriented Coping: Social Diversion, $R^{2}=.44, F(2,37)=14.26, p<.001, \beta=-.51, t=-2.16$, $p=.037$, accounting for $11 \%$ of variance, but not Avoidance-Oriented Coping: Distraction, $R^{2}=.32$, $F(2,37)=8.87, p<.001, \beta=-.47, t=-1.81, p=.079$. State anxiety predicted: Task-Oriented Coping, $R^{2}=.77, F(2,37)=62.07, p<.001, \beta=-.54, t=-3.59$, $p<.001$, accounting for $26 \%$ of variance, Emotion-Oriented Coping, $R^{2}=.88, F(2,37)=130.17, p<.001, \beta=.46$, $t=4.15, p<.001$, accounting for $32 \%$ of variance.

In the criterion group, linear regression indicated that experiencing many stressful situations in life predicted Avoidance Coping: Social Diversion, $R^{2}=.30, F(1,17)=7.22, p=.016, \beta=.55, t=2.69$, accounting for $30 \%$ of variance, and trait anxiety, $R^{2}=.39, F(1,17)=10.99, p=.004, \beta=.63, t=3.32$, accounting for $39 \%$ of variance.

\section{DISCUSSION}

We found that the participants with SFD experienced a higher degree of state and trait anxiety than their peers without SFD, which is consistent with the literature, as high levels of both trait (chronic) and state anxiety were found in adults who stutter (Craig et al., 2003). This higher level was observed even though half of the participants took part in psychological therapy. Moreover, in our study stressful life situations, self-reported by the criterion group, predicted trait anxiety. State anxiety (fear) appears primarily in speech-related situations (Craig et al., 2003). People with SFD experience constant psychological and physical tension, and feel that they cannot meet given expectations and aims (Humeniuk, 2012). Moreover, their effective communication, social participation, academic and occupational performances are limited (APA, 2013).

Our study demonstrated that trait anxiety predicted the employment of Emotion-Oriented Coping (positively), and Task-Oriented and Avoidance-Ori- ented Coping: Social Diversion (negatively). Similarly, we found that state anxiety predicted Emotion-Oriented Coping (positively), and Task-Oriented Coping (negatively). Erdem et al. (2011) suggested that dysfunctional coping strategies are positively associated with anxiety among stuttering adults.

In our study, the participants with SFD more rarely used Task-Oriented Coping style than the controls did, not trying to proactively eliminate the problem itself. Disfluencies in stuttering are perceived as uncontrollable, incurable, and lifelong stressors that cannot be simply solved in a constructive manner nor emotionally endured for a long period of time (Plexico et al., 2009).

We found that the participants with SFD more often used Emotion-Oriented Coping than their peers without SFD. They relied on dealing with internal feelings and wishful thinking, focusing on experienced negative emotions, which leads to anger and tension. Negative emotions experienced by people who stutter include shame, guilt, and embarrassment (Błachnio \& Przepiórka, 2012). This kind of attitude affects relations with others, and results in academic failures, lower work efficiency, and the constant feeling of danger and inferiority (Kostecka, 2004).

In our study, the participants with SFD, despite relying on Emotion-Oriented Coping, less often used Avoidance-Oriented Coping: Distraction and Social Diversion than the controls did. Moreover, Avoidance-Oriented Coping: Social Diversion was predicted by stressful life situations experienced by the criterion group. This is in contradiction to Plexico et al. (2009) findings that individuals who stutter primarily use an embedded pattern of avoidance, which seems to be a quick and temporarily effective solution for handling anxiety, in spite of the stutterers' awareness that it brings no permanent positive change. We believe that a lower score of our participants in Avoidance-Oriented Coping: Distraction and Social Diversion may be related to their lower social skills. Adverse psychological and social results of stuttering occur as early as the beginning of formal education (Crichton-Smith, 2002). Students who stutter experience negative reactions to their problem from the teachers (Crichton-Smith, 
2002). Thus, stuttering may significantly reduce the quality of school functioning and academic achievements (Klompas \& Ross, 2004), result in a defensive attitude, social withdrawal, socializing only with closest friends and family (Humeniuk, 2012), as well as influencing one's choices regarding further education and professional development. Avoiding public speaking and conversations with strangers, dodging or substituting challenging words, and engaging in non-verbal activities are some of the common tactics aiming to manage the discomfort of public speaking (Blumgart et al., 2010; Plexico et al., 2009). Moreover, people with SFD have low self-esteem and self-assessment, which hampers their self-development, lowers their ambitions, and leads to pursuing aims below their capabilities (Humeniuk, 2012). A majority of adults with SFD perceive stuttering as a serious limitation to finding employment, performing their duties, or receiving promotion (Klompas \& Ross, 2004).

\section{LIMITATIONS}

Although we carefully prepared this research, numerous limitations need to be considered and addressed in future studies. First, the number of study participants is small, and therefore the results cannot be generalized to the population of persons with SFD. The small size of the criterion group results directly from the fact that persons with SFD are a very specific group that represents a fairly small portion of the population. This is also a reason why the participants' age ranges widely, which should be considered as another limitation of this study. Future research should look at differences in experiencing stress, levels of trait and state anxiety, as well as coping strategies among persons with SFD at different age and life stages, while also considering their gender (Guszkowska, Zagórska-Pachucka, Kuk, \& Skwarek, 2016). Persons in early, middle, and late adulthood may have distinctive professional and personal stuttering related experiences and may vary in their interpretation, which may play an important role in the amount of experienced stress, anxiety, or the type of preferred coping strategies. For instance, adolescents with SFD entering into young adulthood, like their peers, presumably may still be in the process of developing strategies to cope with adverse situations. Therefore, it would also be advisable to examine the family support in their stress managing techniques. Moreover, the actual level of educational and professional achievement could be analyzed, including the planned and pursued career plan, to investigate whether the participants would refrain from jobs involving public speeches or social interactions. A follow-up to the study could be a detailed analysis within the criterion group of psychological therapy, that all our participants who stuttered attended, and its influence of the anxiety level and coping strategies.

\section{CONCLUSIONS}

Our study confirmed that persons with SFD feel greater anxiety, both as a trait and as a state, which influences their daily life. Moreover, self-reported stressful life situations predicted trait anxiety in the criterion group. The participants with SFD, as compared with participants without SFD, more often used Emotion-Oriented Coping, and less often Task-Oriented and Avoidance-Oriented Coping: Social Diversion and Distraction. Trait anxiety contributed to their preferred use of Emotion-Oriented coping strategies, at the expense of Avoidance-Oriented Coping: Social Diversion and more proactive Task-Oriented Coping. State anxiety predicted the employment of Emotion-Oriented (positively), and Task-Oriented (negatively) Coping. Experienced stress and anxiety had influenced and consolidated their habitual stress coping styles, devoted mainly to dealing with negative emotions. As stuttering impedes functional communication, it affects various aspects of a person's life, including interpersonal relationships (Blumgart et al., 2010), and its overall quality (Koedoot et al., 2011). Therefore, a focus of professional support, in addition to speech therapy, should be the implementation of effective, adaptive, Task-Oriented coping, as well as building assertiveness, self-esteem, and social skills to increase adaptation and life satisfaction.

\section{REFERENCES}

American Psychiatric Association (APA). (2013). Diagnostic and statistical manual of mental disorders ( $5^{\text {th }}$ ed.). Arlington, VA: American Psychiatric Publishing.

Blumgart, E., Tran, Y., \& Craig, A. (2010). Social anxiety disorder in adults who stutter. Depression and Anxiety, 27, 687-692.

Błachnio, A., \& Przepiórka, A. (2012). Jąkanie jako zaburzenie z perspektywy psychologicznej: przegląd badań [Stuttering as a disorder from a psychological perspective: A review of research]. Psychologia Jakości Życia, 11, 211-222.

Carver, C. S., \& Scheier, M. F. (1994). Situational coping and coping dispositions in a stressful transaction. Journal of Personality and Social Psychology, 66, 184-195.

Craig, A., Hancock, K., Tran, Y., \& Craig, M. (2003). Anxiety levels in people who stutter. A randomized population study. Journal of Speech, Language, and Hearing Research, 46, 1197-1206. 
Craig, A., \& Tran, Y. (2006). Fear of speaking: chronic anxiety and stammering. Advances in Psychiatric Treatment, 12, 63-68.

Crichton-Smith, I. (2002). Communicating in the real world: Accounts from people who stammer. Journal of Fluency Disorders, 27, 333-352.

Erdem, M., Çelik, C., Doruk, A., Özgen, F., \& Özşahin, A. (2011). Genç erişkin kekemelik vak'alarinda anksiyete düzeyi ile başa çikma tutumlarinin ilişkisi [Relation of anxiety levels and coping strategies in young and adult stutterers]. Yeni Symposium, 49, 77-82.

Guszkowska, M., Zagórska-Pachucka, A., Kuk, A., \& Skwarek, K. (2016). Gender as a factor differentiating strategies of coping with stress used by physical education students. Health Psychology Report, 4, 237-245.

Humeniuk, E. (2012). Biologiczne i psychologiczne aspekty jąkania [Biological and psychological aspects of stuttering]. Lublin: Uniwersytet Medyczny w Lublinie.

Klompas, M., \& Ross, E. (2004). Life experiences of people who stutter, and the perceived impact of stuttering on quality of life: Personal accounts of South African individuals. Journal of Fluency Disorders, 29, 275-305.

Koedoot, C., Bouwmans, C., Franken, M. C., \& Stolk, E. (2011). Quality of life in adults who stutter. Journal of Communication Disorders, 44, 429-443.

Kostecka, W. (2004). Zintegrowany program terapii osób jąkajacych się [Integrated programme of the therapy of people who stutter]. Lublin: AWH Antoni Dudek.

Namasivayam, A. K., \& van Lieshout, P. (2008). Investigating speech motor practice and learning in people who stutter. Journal of Fluency Disorders, 33, 32-51.

Plexico, L. W., Manning, W. H., \& DiLollo, A. (2005). A phenomenological understanding of successful stuttering management. Journal of Fluency Disorders, 30, 1-22.

Plexico, L. W., Manning, W. H., \& Levitt, H. (2009). Coping responses by adults who stutter: Part I. Protecting the self and others. Journal of Fluency Disorders, 34, 87-107.

Sosnowski, T., Wrześniewski, K., Jaworowska, A., \& Fecenec, D. (2011). The State-Trait Anxiety Inventory. Warszawa: Pracownia Testów Psychologicznych Polskiego Towarzystwa Psychologicznego.

Strelau, J., Jaworowska, A., Wrześniewski, K., \& Szczepaniak, P. (2005). The Coping Inventory for Stressful Situations (CISS). Warszawa: Pracownia Testów Psychologicznych Polskiego Towarzystwa Psychologicznego.

World Health Organization (WHO) (1992). The ICD10 classification of mental and behavioural disorders: clinical descriptions and diagnostic guidelines. Geneva: World Health Organization.
Vanryckeghem, M., Brutten, G. J., Uddin, N., \& Van Borsel, J. (2004). A comparative investigation of the speech-associated coping responses reported by adults who do and do not stutter. Journal of Fluency Disorders, 29, 237-250. 